\title{
Estimating Volume of Water Harvested by Farm Dams in Murray-Darling Basin
}

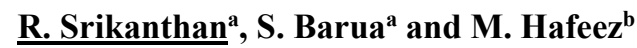 \\ ${ }^{a}$ Bureau of Meteorology, 700 Collins Street, Melbourne, Australia \\ ${ }^{b}$ Bureau of Meteorology, 69 Ann Street, Brisbane, Australia \\ Email: s.srikanthan@bom.gov.au
}

\begin{abstract}
With limited water resources available, farmers in many parts of Australia have resorted to building farm dams to supplement water for irrigation and stock. While the impact of an individual farm dam on a catchment is relatively small, the cumulative impact on runoff from a large number of farm dams on may be significant. To give an example of scale, the Murray-Darling Basin (MDB) has over 650,000 farm dams at present. This paper aims to quantify the effect of the farm dams on the water resources in the Murray-Darling Basin.
\end{abstract}

Through the Water Act 2007, the Bureau of Meteorology (the BoM) has the responsibility to produce an annual National Water Account (NWA) which provides information on water stores and fluxes, water rights and water use across Australia. The Australian Water Resource Assessment Modelling System (AWRAMS) is being developed by CSIRO and the BoM through the Water Information Research and Development Alliance (WIRADA) initiative. AWRAMS is a new integrated continental hydrological simulation system that has two modeling components to represent processes between the atmosphere and the landscape (AWRA-L) and in gauged rivers (AWRA-R), including all major water storages and fluxes in and between these components (surface, subsurface and groundwater). One of the fluxes described in the NWA is the runoff to rivers/reservoirs accounting for interception and storage by farm dams.

The Spatial Tool for Estimating Farm Dam Impacts (STEDI), developed by SKM, was used in the production of the NWAs for 2010 and 2011. STEDI carries out a water balance for each farm dam at each monthly time step using contributing catchment inflows, rainfall, evaporation and on-farm demand. The contributing catchment inflows were obtained by lumping the contributing catchment's runoff generated by the grid-based AWRA-L model. Running the STEDI model is time consuming in terms of preparing and inputting the data into the model and applying it over large areas as the number of farm dams in a model run must be less than 10,000 (requiring 105 regions in the case of the MDB). In order to streamline and speed up the production of the NWA, a farm dam model (FDM) similar to STEDI was coded in FORTRAN, run over the NWA Canberra region and then evaluated by comparing the results to those from the original STEDI model. Following successful evaluation, the developed FDM model was applied to the recent NWAs (NWA 2011, NWA 2012, NWA 2013 and NWA 2014) over the MDB.

The current FDM approach used in the NWA has two limitations: all farm dams are assumed to be directly connected to the catchment outlet and the spatial variation in the input is ignored by lumping them. Also, currently the farm dam modelling is undertaken separate from the AWRAMS although there are plans to integrate the two in the future. This paper will present the development of a farm dam model and its application to the MDB for the production of the NWA reports. Future direction of farm dam modeling through model integration with the BoM's operational AWRAMS is also presented at the end of the paper.

Keywords: Farm dam modelling, water harvesting, National Water Account, Murray-Darling Basin 


\section{INTRODUCTION}

Australia is often considered the driest inhabited continent in the world, yet it has much variability in water availability with areas ranging from water rich to water scarce. The Murray Darling Basin (MDB) is the largest river basin in Australia and is generally considered its 'food bowl' due to its important agricultural production. The MDB suffered a prolonged drought from 1997-2009 known as the millennium drought, during which rivers within the MDB received 40 percent less inflow than was the long term average (Saha, 2015). In order to overcome the water scarcity, many farmers constructed small farm dams with volumes approximately ranging from 0.2 to $100 \mathrm{ML}$ (CSIRO, 2007). Farm dams are typically earth structures designed to capture and store water for irrigation, aquaculture, stock watering, domestic supply or aesthetic purposes (Lewis, 2002). These farm dams have been shown to store up to 2,168 GL of water in the Basin and can act as a significant interceptor to runoff, potentially reducing stream flow (SKM, 2007). Reduced streamflow in the rivers can affect the health of many precious riparian flora and fauna that live in or near the river. SKM (2007) have carried out a study projecting new farm dams to 2030 and assessed the future impact of farm dams on runoff in the MDB. The findings of the study are the volume of water stored in farm dams will increase to $2428 \mathrm{GL}$ (net increase of $228 \mathrm{GL}$ ) and runoff to rivers and storages will be reduced to 180 GL in 2030. Considering high competition among various sectors for scarce water, there is an urgent need to monitor water flows and usage more carefully for agriculture production within the MDB.

Knowledge of the hydrology on irrigated farms within the inundation plains of the MDB is limited in quality, and reliability of the observation network that has been declining rapidly over the past few decades (Hafeez et al., 2011). While the impact of an individual farm dam on a catchment is relatively small, the cumulative impact of a large number of farms on runoff may be significant. As an example of scale, the MDB has over 650,000 farm dams at present (Leslie, 2005). It therefore becomes necessary to quantify the effect of farm dams on the water resources. Improved estimates of the volume of water stored in farm dams will guide water management decisions at farm to catchment scale and could be instrumental for enhancing the integrity of the water allocation process and making it more fair and equitable across stakeholders in the MDB. Since 2008, Australian Government has been buying back water entitlements from individual farmers to maintain environmental flows and to secure water for cities as part of the Water Smart Australia initiative.

Accurate estimation of the volume of water stored in the small dams scattered around the MDB is complex and scientifically challenging. Traditionally, volumes of water stored in farm dams are estimated by conducting a bathymetric survey of each farm dam but this is time consuming and costly (Hafeez et al., 2007). Remote sensing-based volumetric assessment of water stored in farm dams has been successfully applied in Australia and overseas (Hafeez et al., 2007, Chemin and Rabbani, 2011) using high spatial resolution satellite imagery, however this needs to be coupled with either bathymetric survey or a high resolution digital elevation model to derive depth-area-volume relationships for accurate volume estimation.

In Australia, many operational water balance models have been developed to estimate volumes of water stored in farm dams for various catchments. Each model has its merits and weaknesses. A starting point was the Tool for Estimating Dam Impacts (TEDI model) developed by ICAMC and SKM (1999), a simple computer program that assesses the impacts of farm dams on streamflow at catchment scales. However, the TEDI model cannot represent farm dams spatially in the catchment. To overcome this limitation, the Complete Hydrological Evaluation of the Assumptions in TEDI (CHEAT model) was developed by Nathan et al. (2005) using a spatially explicit network of all farm dams in a study catchment. Building on the CHEAT model functionality, SKM later developed the Spatial Tool for Estimating Dam Impacts (STEDI model), a Windows-based computer program for simulating the impact of farm dams on streamflows within the MDB (SKM, 2011). The STEDI model allows the user to spatially configure a network of dams in any catchment so that inflows are influenced by upstream dams. The STEDI model has been primarily used as an input to larger surface water models like REALM and SOURCE.

Most recently, the Bureau of Meteorology (the BoM) has developed an operational daily water balance model called the Australian Water Resources Assessment Modelling System (AWRAMS), a new integrated continental hydrological simulation system which is mainly used for water accounting and water resources assessment purposes (Hafeez et al., 2015). The AWRAMS has two modeling components that represent processes between the atmosphere and the landscape (AWRA-L) and processes in gauged rivers (AWRA-R), including all major water storages and fluxes in and between these components (surface, subsurface and groundwater). In order to estimate the volume of water stored in farm dams, the BoM team has developed a farm dam model (FDM) coded in FORTRAN that is conceptually similar to STEDI and mainly used for water accounting purposes in the MDB. One of the important fluxes in the National Water Account (NWA) is the runoff to rivers/reservoirs accounting for interception and storage by farm dams. 
The purpose of this paper is to use the FDM model to estimate farm dam water storage volumes within selected catchments of the MDB and compare this with the estimate from the STEDI model.

\section{STUDY AREA}

The MDB, the study area, is the catchment of the Darling $(2,740 \mathrm{~km})$ and Murray $(2,520 \mathrm{~km})$ Rivers including their tributaries and is located in the south east of Australia. The MDB is the largest river basin in Australia, covering one seventh of the mainland and falling within Queensland, New South Wales, Victoria, South Australia and the Australian Capital Territory. The MDB contains 40 percent of Australia's farms, 65 percent of its irrigated land and produces one-third of the national food supply (MDBA, 2014). The gross value of irrigated agricultural production was $\$ 4,349$ million in 2008-09 and increased to $\$ 6,691$ million in 2011-12 following the end of the Millennium drought in 2010 (MDBA, 2014). The region has a population of over 2 million, and irrigated agriculture is a major industry. The MDB has been divided into 19 catchments for managing surface water resources as shown in Figure 1. The more than 650,000 farm dams in the MDB (Figure 1) are mainly used for irrigation purposes. Long term average rainfall (1900-2014) is 470 $\mathrm{mm}$ which varies widely from northern catchments to southern catchments. Annual rainfall ranges from more than 1,200-1,800 $\mathrm{mm}$ across the southern areas of the region to less than $300 \mathrm{~mm}$ in the west (BOM, 2014).

The NWA Canberra region is located in the southeast of Australia and within the MDB. It is home to approximately 426,000 people and covers an area of 4,202 $\mathrm{km}^{2}$ (BoM, 2015). The region is characterized by forested mountains in the south and west of the region and plains in the north. The Murrumbidgee River is the main waterway running through the region and its tributaries within the NWA Canberra region include the Cotter, Gudgenby, Molonglo and Queanbeyan Rivers. The long-term average rainfall within the region is about $794 \mathrm{~mm}$ (period 1900-2014). In terms of water resources management, the NWA Canberra region has significant importance to the city of Canberra, the largest urban center within the MDB.

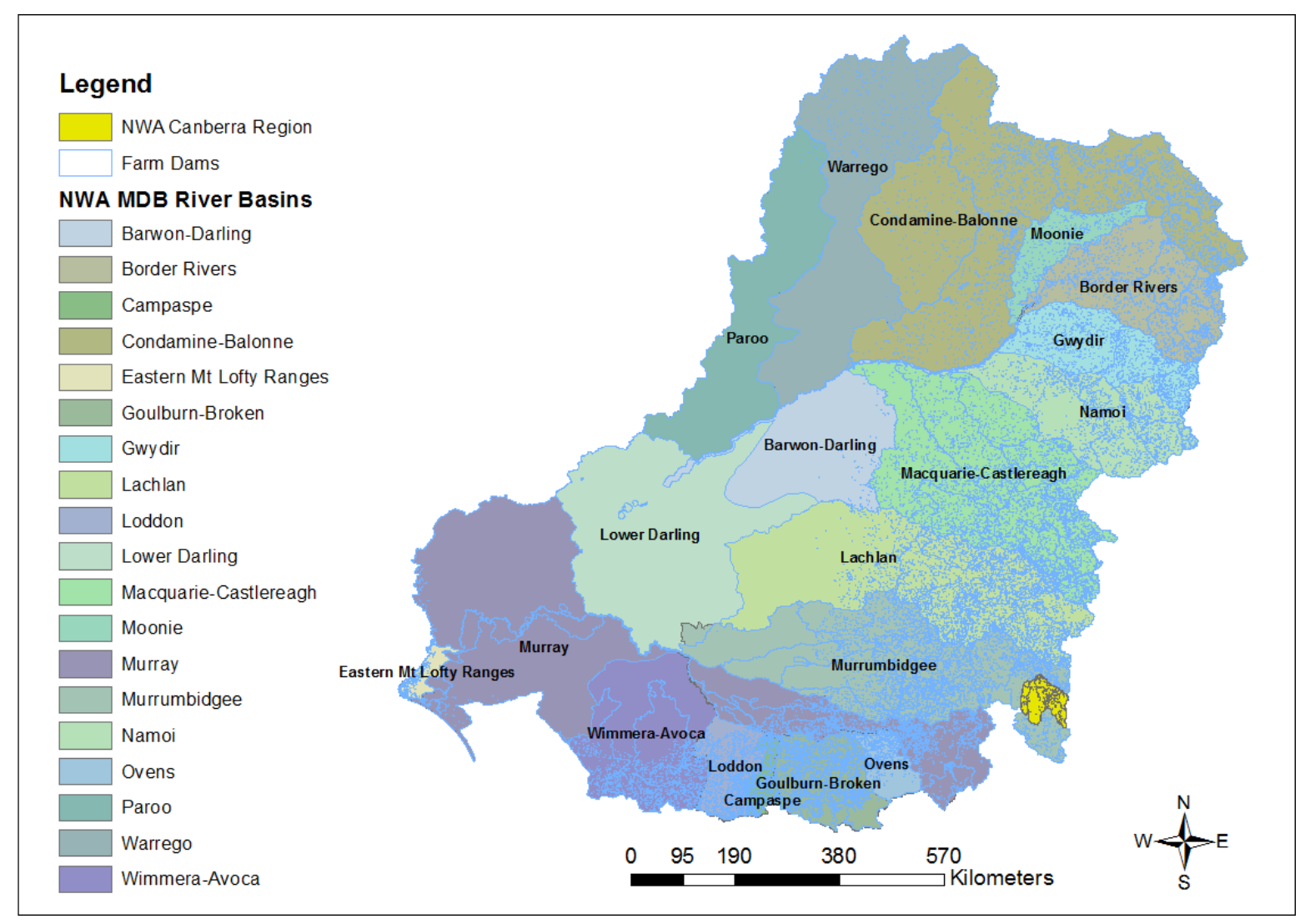

Figure 1. Catchments within the Murray Darling Basin

\section{METHODOLOGY}

The STEDI model (SKM, 2011) was used during the production of NWAs in 2010 (BoM, 2011) and 2011 (BoM, 2012). This tool was used to assess the effect of farm dams on runoff, and can generally handle up to 10,000 farm dams per model. The STEDI tool uses a graphical user interface that makes it time consuming to 
input data and post-process outputs for the NWA, especially when users need to deal with the tens of thousands of farm dams covering a large area such as Murray Darling Basin (MDB). It was decided to develop a farm dam model (FDM) that adopted a similar concept to the STEDI model but overcame these limitations.

The FDM developed in this paper is a water balance model of farm dams. The inputs to this model are rainfall, evaporation, catchment runoff and demand. Like the STEDI model, spill from any farm dam in the catchment is assumed to flow directly to the catchment outlet. Index $j$ is used to represent whether the farm dam is used for stock and domestic $(j=1)$ or for irrigation $(j=2)$. A capacity threshold $\left(\mathrm{C}_{\mathrm{th}}\right)$ is used to determine the type of dam use. If the capacity of the farm dam is greater than $C_{t h}$ then it is assumed to be used for irrigation. Otherwise, it is assumed to be used for stock and domestic purposes. The water balance of farm dam $i$ for month $t$ is given as follows:

$$
\mathrm{S}_{\mathrm{i}}(\mathrm{t})=\mathrm{S}_{\mathrm{i}}(\mathrm{t}-1)+\mathrm{Q}_{\mathrm{t}} \mathrm{CA}_{\mathrm{i}}+\mathrm{R}_{\mathrm{t}} \mathrm{SA}_{\mathrm{i}}-\mathrm{E}_{\mathrm{t}} \mathrm{SA}_{\mathrm{i}}-\mathrm{Use}_{\mathrm{i}}(\mathrm{t})
$$

where, $S_{i}(t) \quad$ Water storage in farm dam $i$ for month $t(M L)$

$\mathrm{S}_{\mathrm{i}}(\mathrm{t}-1) \quad$ Water storage in farm dam i for month $\mathrm{t}-1$ (ML)

$\mathrm{Q}_{\mathrm{t}} \quad$ Catchment average runoff for month $\mathrm{t}(\mathrm{mm})$

$\mathrm{CA}_{\mathrm{i}}$ Catchment area contributing to farm dam i $\left(\mathrm{Km}^{2}\right)$

$\mathrm{R}_{\mathrm{t}} \quad$ Catchment average rainfall for month $\mathrm{t}(\mathrm{mm})$

$\mathrm{SA}_{\mathrm{i}} \quad$ Surface area of farm dam i $\left(\mathrm{Km}^{2}\right)$

$\mathrm{E}_{\mathrm{t}} \quad$ Catchment average evaporation for month $\mathrm{t}(\mathrm{mm})$

$\mathrm{Use}_{\mathrm{i}}(\mathrm{t}) \quad$ Water use for month $\mathrm{t}\left(=\mathrm{ODF}_{\mathrm{jk}} \mathrm{C}_{\mathrm{i}}\right)(\mathrm{ML})$

$\mathrm{C}_{\mathrm{i}} \quad$ Capacity of farm dam i (ML)

$\mathrm{ODF}_{\mathrm{jk}}$ Overall demand factor for use types $j$ and $k$ ( $k=1$ water use, $k=2$ seepage loss)

Subject to the following conditions:

If $\mathrm{S}_{\mathrm{i}}(\mathrm{t})>\mathrm{C}_{\mathrm{i}} \quad$ Spill $_{\mathrm{i}}(\mathrm{t})=\mathrm{S}_{\mathrm{i}}(\mathrm{t})-\mathrm{C}_{\mathrm{i}}$ and $\mathrm{S}_{\mathrm{i}}(\mathrm{t})=\mathrm{C}_{\mathrm{i}}$

where, $\operatorname{Spill}_{i}(\mathrm{t})$ is the spill from farm dam $\mathrm{i}$

$$
\begin{aligned}
& \text { If } \mathrm{S}_{\mathrm{i}}(\mathrm{t})<0, \quad \mathrm{Use}_{\mathrm{i}}(\mathrm{t})^{*}=\mathrm{Use}_{\mathrm{i}}(\mathrm{t})+\mathrm{S}_{\mathrm{i}}(\mathrm{t}) \text { and } \mathrm{S}_{\mathrm{i}}(\mathrm{t})=0 \\
& \text { If } \operatorname{Use}_{\mathrm{i}}(\mathrm{t})^{*}<0, \quad \operatorname{Evap}_{\mathrm{i}}(\mathrm{t})^{*}=\operatorname{Evap}_{\mathrm{i}}(\mathrm{t})+\mathrm{Use}_{\mathrm{i}}(\mathrm{t})^{*} \text { and } \mathrm{Use}_{\mathrm{i}}(\mathrm{t})^{*}=0 \\
& \text { If } \operatorname{Evap}_{\mathrm{i}}(\mathrm{t})^{*}<0, \quad \operatorname{Evap}_{\mathrm{i}}(\mathrm{t})^{*}=0
\end{aligned}
$$

Total runoff with no farm dams $=\mathrm{Q}_{\mathrm{t}} \mathrm{A}$

where, $\mathrm{A}$ is the total catchment area $\left(\mathrm{km}^{2}\right)$

Total runoff with farm dams $=\max \left(\mathrm{Q}_{\mathrm{t}}\left(\mathrm{A}-\sum \mathrm{CA}_{\mathrm{i}}\right), 0\right)+\sum \sum \operatorname{Spill}_{\mathrm{i}}(\mathrm{t})$

Runoff harvesting $=\mathrm{Q}_{\mathrm{t}} \sum \mathrm{CA} \mathrm{A}_{\mathrm{i}}-\sum \sum \operatorname{Spill}_{\mathrm{i}}(\mathrm{t})$

Precipitation of off-channel storages $=\sum \mathrm{R}_{t} \sum \mathrm{SA}_{\mathrm{i}}$

Evaporation from off-channel storages $=\sum \sum$ Evap $_{\mathrm{i}}(\mathrm{t})$

Water use $=\sum \sum \mathrm{Use}_{\mathrm{i}}(\mathrm{t})$

Spill $=\sum \sum \operatorname{Spill}_{\mathrm{i}}(\mathrm{t})$

Each farm dam is modelled separately and aggregated over the catchment to obtain the total stored water volume. At the start, all farm dams are assumed to be empty. Runoff from the contributing area and rainfall falling on the farm dam are added while water use and evaporation from the farm dam are subtracted from the starting storage of the dam. At the end of each time step, there are three possibilities.

1. Storage value lies between zero and the capacity of the farm dam; proceed to the next time step. 
2. Storage value is greater than the capacity of the farm dam; farm dam spills and the storage is set to the capacity of the farm dam.

3. Storage value is less than zero; water in the dam is not sufficient to meet the evaporation and water use demand. Demand is first reduced so that the storage becomes zero. If this is not enough to bring the storage to zero, then the evaporation is reduced so that the storage is become zero.

The above procedure is repeated for all time steps where input data are available.

\section{RESULTS AND DISCUSSION}

The developed FDM was applied to the NWA Canberra region (BoM, 2015) so as to compare with results obtained from the STEDI model for 2010-11 and 2011-12. Due to the limitation on the maximum number of farms dams that can be represented in the STEDI model, the Canberra region was divided into five subregions to run. The results from each model are presented in Table 1 both for the five sub-regions and for the whole region.

Table 1. Comparison of the results from the STEDI and FDM

\begin{tabular}{|c|c|c|c|c|c|c|c|}
\hline \multicolumn{2}{|c|}{ Catchment } & Bendora & Canberra downstream & Corin & Cotter & Googong & Total \\
\hline \multicolumn{8}{|c|}{ Off-channel water storages (ML) } \\
\hline \multirow[b]{2}{*}{ 2010-11 } & STEDI & 29 & 6648 & 4 & 9 & 1409 & 8098 \\
\hline & FDM & 29 & 6656 & 4 & 9 & 1412 & 8110 \\
\hline \multirow[b]{2}{*}{$2011-12$} & STEDI & 29 & 7025 & 4 & 9 & 1455 & 8522 \\
\hline & FDM & 29 & 7034 & 4 & 9 & 1458 & 8534 \\
\hline \multicolumn{8}{|c|}{ Precipitation on off-channel water store (ML) } \\
\hline \multirow[b]{2}{*}{$2010-11$} & STEDI & 19 & 5189 & 7 & 15 & 1136 & 6365 \\
\hline & FDM & 19 & 5188 & 7 & 15 & 1136 & 6364 \\
\hline \multirow[b]{2}{*}{$2011-12$} & STEDI & 18 & 5164 & 6 & 14 & 1185 & 6387 \\
\hline & FDM & 18 & 5164 & 6 & 14 & 1186 & 6387 \\
\hline \multicolumn{8}{|c|}{ Runoff harvesting into off-channel water store (ML) } \\
\hline \multirow[b]{2}{*}{ 2010-11 } & STEDI & 29 & 5609 & -1 & -1 & 915 & 6551 \\
\hline & FDM & 29 & 5644 & -1 & -1 & 915 & 6586 \\
\hline \multirow[b]{2}{*}{$2011-12$} & STEDI & 7 & 3764 & -1 & 0 & 676 & 4447 \\
\hline & FDM & 7 & 3792 & -1 & 0 & 676 & 4475 \\
\hline \multicolumn{8}{|c|}{ Evaporation from off-channel private storages (ML) } \\
\hline \multirow[b]{2}{*}{ 2010-11 } & STEDI & 11 & 4634 & 3 & 9 & 1042 & 5699 \\
\hline & FDM & 11 & 4636 & 3 & 9 & 1042 & 5701 \\
\hline \multirow[b]{2}{*}{$2011-12$} & STEDI & 11 & 4617 & 4 & 9 & 1052 & 5693 \\
\hline & FDM & 11 & 4624 & 4 & 9 & 1053 & 5701 \\
\hline \multicolumn{8}{|c|}{ Water use (ML) } \\
\hline \multirow[b]{2}{*}{ 2010-11 } & STEDI & 14 & 4128 & 2 & 5 & 791 & 4939 \\
\hline & FDM & 14 & 4134 & 2 & 5 & 791 & 4946 \\
\hline \multirow[b]{2}{*}{$2011-12$} & STEDI & 14 & 3931 & 2 & 5 & 762 & 4714 \\
\hline & FDM & 14 & 3931 & 2 & 5 & 762 & 4715 \\
\hline
\end{tabular}

Table 1 shows that the results from the developed FDM model are similar to those from the STEDI model which provides confidence. The differences between the results from the two models are small and the largest percentage difference is 0.6 percent for the whole Canberra region. Based on this evaluation, the Bureau decided to use the FDM model to estimate the volume of water stored in farm dams within the entire MDB for NWA purposes.

To model the whole of the MDB it was divided into 105 regions for the purposes of modelling the farm dams. The AWRA-L model input and output provided catchment average rainfall, evaporation and runoff which were calculated for each of the 105 regions as the mean occurring across the relevant grid points within the region boundary. Points were weighted by the area they represented to remove edge effects (where the area represented was not wholly within the MDB region) and the effect of changing area represented with changing latitude. The FDM was applied to NWAs for four time water years (i.e., 2010-11, 2011-12, 2012-13 and 2013-14). The results of the 18 modeled catchments are presented in Table 2. It should be noted that modeling was not done for the Lower Darling as there were no farm dams represented in the available data for this region. The lowest number of farm dams appears in the Paroo catchment and the highest number occurs in the Macquarie-Castlereagh catchment. Rainfall appears to be the main factor affecting the magnitude of the values in Table 2. It can be seen from Table 3 that a large volume was harvested each year in farm dams, ranging from 1,004 GL (in 2013-14) to 1,516 GL (in 2010-11). It can also be noticed in Table 3 that there was considerable water use from the farm dams, ranging from 710 GL (in 2013-14) to 1,107 GL 
(in 2010-11). This shows that farm dams have a significant impact on managing scarce water resources in the MDB.

Table 2. Results of various catchments in MDB using the FDM

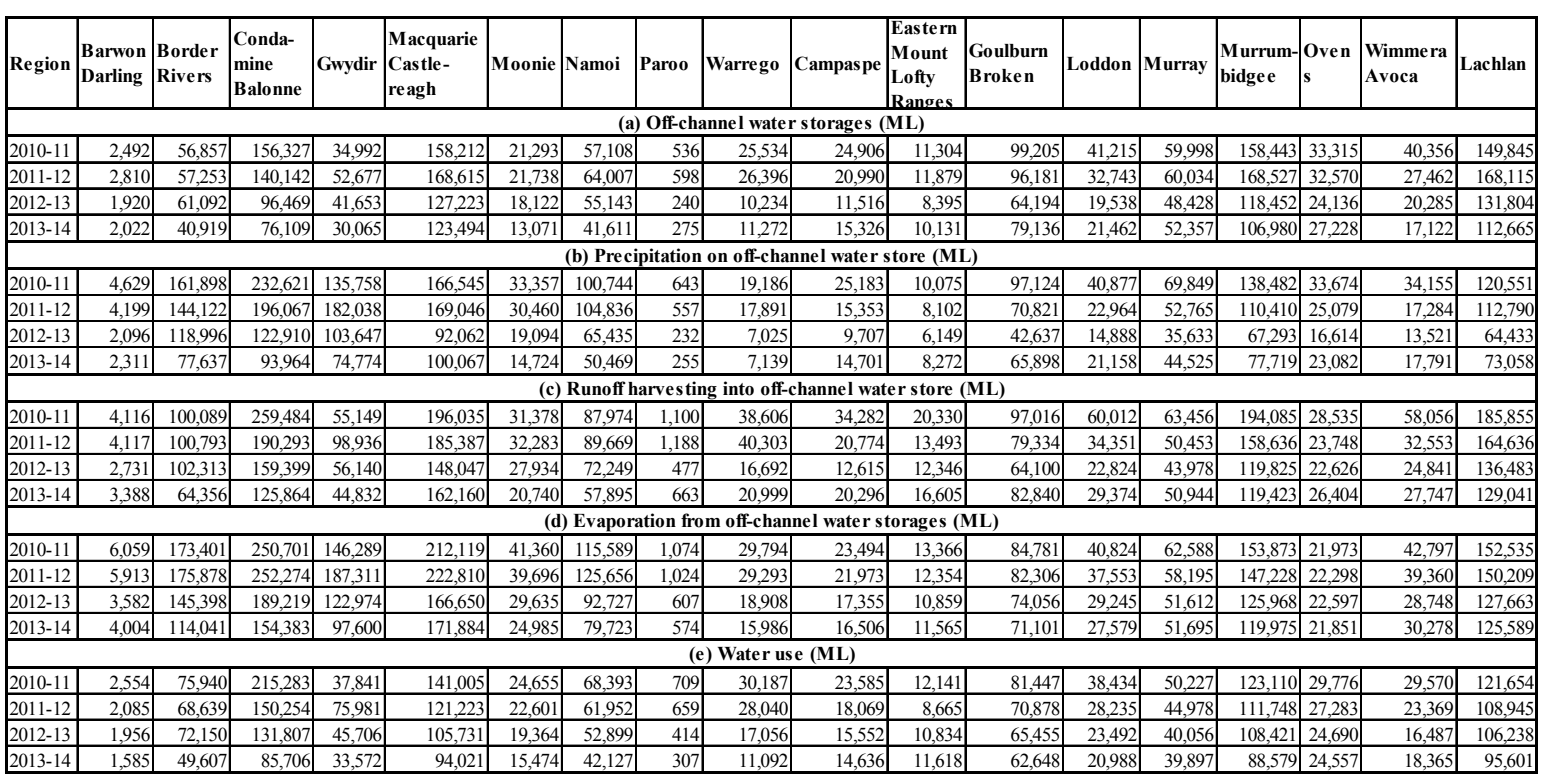

Table 3. Results for the whole MDB

\begin{tabular}{|l|r|r|r|r|}
\hline Reporting line item in NWA & $2010-11$ & $2011-12$ & \multicolumn{1}{|c|}{$2012-13$} & $2013-14$ \\
\hline Off-channel water storages & 1,132 & 1,153 & 859 & 781 \\
\hline Precipitation on off-channel water store & 1,425 & 1,285 & 802 & 768 \\
\hline Runoff harvesting into off-channel water store & 1,516 & 1,321 & 1,046 & 1,004 \\
\hline Evaporation from off-channel water storages & 1,573 & 1,611 & 1,258 & 1,139 \\
\hline Water use & 1,107 & 974 & 858 & 710 \\
\hline
\end{tabular}

There are about 210,350 farm dams in the northern and 379,820 in the southern part of the MDB. Despite the greater number of farm dams in the south, the north has greater total capacity which implies that on average the farm dams in the north are larger than those in the south. The rainfall over the MDB has decreased from $779 \mathrm{~mm}$ in 2010-11 to $388 \mathrm{~mm}$ in 2013-14 and this pattern in evident in the fluxes shown in the Table 2.

In summary, the application of the FDM in NWAs for the MDB region was quite efficient and required less run time (a few days compared to more than a week for STEDI) in terms of processing the inputs and outputs while dealing with large numbers of farm dams located within the MDB.

\section{CONCLUSIONS AND FUTURE WORK}

Due to the limitations in the STEDI model, a FDM was developed and successfully verified against the STEDI model. Subsequently, the FDM was applied to estimate the volume of water stored at the farm dams as part of the NWA for the MDB region. This model has been used to produce the farm dam related items for the National Water Accounts since 2012.

At present, the farm dam modeling has been performed independently to the operational AWRAMS and the impacts of their flow interception is overlooked most of the NWA region. However, it has shown that there is a significant impact of farm dams on catchment runoff within the MDB. Therefore, it is planned to incorporate the farm dam modeling into the AWRAMS in the near future. The integration of the FDM model with the operational AWRAMS will allow assessment of farm dam impact on catchment runoff which is an 
input to the AWRA-R. It will be a two stage processes. In the first stage, the runoff from the AWRA-L will be modified by running the FDM model. In the second stage, the modified runoff will be used as an input for the AWRA-R model unlike the current FDM approach where catchment runoff from AWRA-L is given as an input to AWRA-R without considering the farm dam impacts.

\section{REFERENCES}

BoM (Bureau of Meteorology) (2011). National Water Account 2010, [http: http://www.bom.gov.au/water/nwa/2010/], (accessed July 8, 2015).

BoM (Bureau of Meteorology) (2012). National Water Account 2011, [http: http://www.bom.gov.au/water/nwa/2011/], (accessed July 8, 2015).

Bureau of Meteorology (2014) State of the climate 2014. Bureau of Meteorology

BoM (Bureau of Meteorology) (2015). National Water Account (NWA) Canberra Region, [http://www.bom.gov.au/water/nwa/2014/canberra/index.shtml], (accessed July 10, 2015).

CSIRO (2007) Rainfall-Runoff Modelling Technical Report, Murray-Darling Basin Sustainable Yields Project, CSIRO, Canberra

Chemin Y, and Rabbani U (2011) Monitoring On-Farm Water Storage Use: From LIDAR to Multi-Source Remote Sensing, International Journal of Geoinformatics, Vol. No. 7 (3): Pages 1-6

Hafeez M, Andreini M, Liebe J, Friesen J, Marx A., and Giesen N. (2007) Hydrological parameterization through remote sensing in Volta Basin, West Africa International Journal of River Basin Management, Vol no.: 5(1), Pages 49-56

Hafeez MM, Edraki M, Rabbani U, Chemin Y., Ullah MK., and Sixsmith J. (2011) A spatial hydrological model for estimation of unaccounted water diversions in the northern Murray-Darling Basin of Australia. International Association of Hydrological Sciences (IAHS) Red Book Series on Grace, Remote Sensing and Ground-based Methods in Multi-Scale Hydrology by Hafeez MM et al., (Eds), Volume 343; Pages 196: 41-46 ISBN 978-1-907161-18-6

Hafeez MM, Frost A, Vaze J, Dutta D, Smith A, Elmahdi A (2015) A new integrated continental hydrological simulation system: An overview of the Australian Water Resource Assessment Modelling System (AWRAMS), Australian Water Association Water Journal, May 2015: Page 75-82

ICAM (Integrated Catchment Assessment and Management Centre) and SKM (Sinclair Knight Merz.) (1999), Impacts and implications of farm dams on catchment yield, Report prepared for the MurrayDarling Basin Commission.

Lewis, B. (2002). Farm Dams, Planning, Construction and Maintenance, CSIRO Publishing.

Leslie, J. (2005) Deep water - The epic struggle over dams, displaced people and the environment. Farrar, Straus and Giroux Publication, $352 \mathrm{pp}$

MDBA (2014) The basin authority. http://www.mdba.gov.au/about-basin/basin-economy/basinagriculture. Accessed 14th July 2015

Nathan, R., Jordan, P. and Morden, R. (2005), Assessing the impact of farm dams on streamflows, Part I: Development of simulation tools. Australian Journal of Water Resources, 9, 1-11

Saha Partha (2015) Hydrological Modeling to Assess Water Availability in the Murrumbidgee Catchment in Response to Different Climate and Land Use Change Scenarios, PhD Thesis, Charles Sturt University

SKM (Sinclair Knight Merz.) (2007) Projections of Effect of Future Farm Dam Development to the year 2030 on Runoff Murray Darling Basin Sustainable Yields Project, Pages 150

SKM (Sinclair Knight Merz.) (2011). STEDI - Tool for estimating the impact of farm dams on streamflow, User Manual Version 1.1, 32 pp.

SKM (2014). Modelling of Farm Dam Impacts: Modelling results report. SKM, Sydney, 33pp. 